\title{
JURISPRUDENCIA AMBIENTAL EN LA RIOJA (PRIMER SEMESTRE 2018)
}

\author{
María del Carmen Bolaño Piñeiro \\ Profesora Adjunta de Derecho Administrativo \\ Universidad del País Vasco / Euskal Herriko Unibertsitatea
}


Sumario. 1. Panorámica general. 2. Vertidos.

\section{PANORÁMICA GENERAL}

Como viene siendo habitual, son escasas las sentencias dictadas en materia medioambiental por el Tribunal Superior de Justicia de La Rioja. Tanto es así que en el semestre objeto de recopilación tan solo se encuentra una sentencia en materia administrativa sancionadora por vertidos al dominio público hidráulico.

\section{VERTIDOS}

La sentencia del Tribunal Superior de Justicia de La Rioja 68/2018, de 26 de febrero, tiene como objeto el análisis de la resolución de la Confederación Hidrográfica del Ebro de 7 de abril de 2015, por la que se impone una multa de $2.000 €$ al ayuntamiento de Alfaro por el vertido de aguas residuales en condiciones no autorizadas al dominio público hidráulico, en concreto al río Alhama.

Los servicios técnicos del Área de Control de Vertidos levantaron acta documentada de la presencia de aguas residuales industriales en una zona situada en la escollera que protege el fondo del barranco de Putete, circulando los vertidos por una vía de ferrocarril hasta el río Alhama. El Tribunal da la razón a la Confederación Hidrográfica del Ebro basándose en dichos hechos que da por probados al no presentarse prueba en contrario por el ayuntamiento de Alfaro. En concreto, a juicio del tribunal los hechos encajan en las infracciones tipificadas en los artículos 116.3.f) del Texto Refundido de la Ley de Aguas y el art. 315 del Reglamento del Dominio Público Hidráulico. Asimismo, entiende el tribunal que la sanción de $2.000 €$ es proporcionada ya que dicho montante económico se encuentra dentro del baremo establecido en el artículo 117 de la Ley de Aguas para las infracciones leves, pudiendo llegar aquel hasta un máximo de $10.000 €$. 
Por estas razones, la resolución no se anula por el tribunal y desestima el recurso contencioso-administrativo interpuesto por la parte demandante, esto es, el Ayuntamiento de Alfaro. 